\title{
EKOLOGI MEDIA PEMBELAJARAN PAI DAN BP DI SMP ALAM BANYUWANGI
}

\author{
Asep Muljawan \\ STAI Asy-Syukriyyah \\ asep.muljawan@asy-syukriyyah.ac.id \\ Moh. Ni’am Mulloh \\ Pascasarjana Institut Agama Islam Negeri Jember \\ Niammulloh1212@gmail.com
}

\begin{abstract}
The ecological crisis is believed to have contributed to the destruction of human survival, namely a condition in which the ecological system is disturbed or even imbalanced. Through the world of education that fosters ecological character, It is hoped that it will prove to be a viable option. to this phenomenon. The ecological character aims to increase ecological piety, considering that the ecological crises that have occurred so far are more caused by human attitudes that are not wise in interacting with their environment. Banyuwangi Alam Junior High School with the concept of nature-based learning provides a breath of fresh air for education in Indonesia in developing the character of ecological wisdom, with learning media for the ecology of PAI and BP as well as ecological interactions between students and learning media.
\end{abstract}

Keywords: media, ecology.

\section{PENDAHULUAN}

Manusia adalah makhluk Fungsi khalifah di muka bumi telah diserahkan oleh Tuhan. Pengertian tersebut merujuk pada penegasan Dalam ayat 30 Q.S. Al-Baqarah, Allah berfirman: menerangkan bahwasannya "sesungguhnya Aku hendak menjadikan khalifah dimuka bumi". 1 Berkaitan tentang pengertian khalifah, sebagian ahli berpendapat bahwasannya "khalifah adalah wakil Allah yang ditugaskan untuk mengelola alam". ${ }^{2}$ Berdasarkan pengertian tersebut dapat kita pahami bahwasannya eksistensi manusia di muka bumi ini adalah unutuk menjaga, merawat dan melestarikan alam dari berbagai ancaman yang berpotensi menimbulkan kerusakan atau mengkonservasi bila telah terjadi kerusakan terhadap alam.

Esensi human pada melaksanakan Sebagai khalifah di bumi ini, dia memiliki tanggung jawab. human dibekali oleh Allah dengan berbagai bentuk fasilitas yang bisa menunjang kehidupannya. Hal ini diisyaratkan termaktub Q.S. Al-Jatsiyah ayat 13 yang menjelaskan

\footnotetext{
${ }^{1}$ Yayasan Penyelenggara Penerjehal Al-Qur'an. Al-Qur'an Terjemah Tiga Bahasa. (Depok: Al-Huda Kelompok Gema Insani. 2009), 8.

${ }^{2}$ Rudi Ahmad Suryadi. Kenali Dirimu: Upaya Memahami Manusia Dalam Al-Qur'an. (Yogyakarta: Depublish, 2015), 125.
} 
bahwasannnya "dan dia yang menundukkan untuk kamu langit apa yang ada di langit dan apa yang ada dibumi semuanya (sebagai anugerah) darinya."” Dalam ayat tersebut ditegaskan bawahwasannya Allah telah memberikan anugerah yang melimpah bagi manusia di mana manusia bisa mengambil manfaat yang tiada tara dari langit dan bumi, sehingga manusia bisa memenuhi kebutuhan bagi kelangsungan hidupnya.

Kendati demikian sebagaimana dijelaskan di atas, perbincangan tentang kerusakan lingkungan dalam kehidupan bermasyarakat kian marak terjadi, seperti yang baru-baru ini terjadi dan sempat menggegerkan masyarakat yaitu terjadinya bencana alam tanah longsor, banjir, kebakaran hutan, pengrusakan fasilitas umum, tawuran antar pelajar, tindakan-tindakan pelecehan seksual, penyalah gunaan obat-obatan terlarang serta gaya hidup merusak lingkungan. Di sinyalir Hal ini terjadi karena campur tangan manusia kurang bijak dalam mengelola lingkungan. Dalam lingkup pendidikan pemahaman teks pelajaran yang kurang komprehensif, berakibat pada minimnya pemahaman secara hirarkis antara pengetahuan yang didapatkan melalui kegiatan belajar dengan realitas kehidupan peserta didik, perkembangan peserta didik cenderung hanya berada pada wilayah kognisinya.

Pada saat ini, lembaga pendidikan harus mampu menghasilkan sudut pandang yang relevan. Untuk memulai, pendidikan harus menanamkan keyakinan bahwa perusakan lingkungan adalah konsekuensi negatif dari aktivitas manusia. Kedua, pendidikan memandang kerusakan lingkungan sebagai realitas negatif yang memerlukan pengorbanan manusia. ${ }^{4}$ Kedua konsep ini sangat penting untuk dipahami oleh pendidik sebagai penghubung timbal balik antara manusia dan lingkungan sehingga tibul karakter kearifan ekologis.

Sebagaimana UU Sisdiknas No. 20 tahun 2003 yang menjadi petunujuk penyelenggaraan pendidikan di Indonesia, mengamanahkan bagi setiap penyelenggara pendidikan supaya Pendidikan diselenggarakan dengan mengikutsertakan seluruh anggota masyarakat dalam penyelenggaraan dan pengawasan mutu pelayanan pendidikan. ${ }^{5} \mathrm{Hal}$ ini menstimulasi tentang sebuah pandangan bahwasannya keterkaitan lingkungan dengan sekolah merupakan sebuah kebutuhan demi mempersiapkan peserta didik yang cakap dalam kehidupan sehari-hari.

Di dalam mewujudkan penyelenggaraan pendidikan ada beberapa tipe sekolah yakni salah satunya sekolah alam. Sekolah alam merupakan salah satu wujud nyata perkembangan

\footnotetext{
${ }^{3}$ Yayasan Penyelenggara Penerjehal Al-Qur'an. Al-Qur'an, ... 992.

${ }^{4}$ Anwari Wmk .2010. Pendidikan Tentang Ekologi. Dalam, Setya Raharja, Jurnal Pendidikan Ekologi: Pemberdayaan Lingkungan Sekitar Untuk Pembelajaran. Uny.

${ }^{5}$ UU. Sisdiknas. Bab III Pasal 4 Ayat 6
} 
pendidikan di Indonesia yang serat dengan nilai-nilai ekologis. Hal ini dibuktikan salah satunya dengan pembelajaran out door dan desain bangunan. Desain bangunan ruang belajar disekolah pada umumnya disebut sebagai "kelas" yaitu berupa ruangan tertutup. Namun, istilah ruang beajar dalam Sekolah Alam disebut sebagai "saung", yaitu berupa bangunan yang difungsikan sebagai ruang kelas tanpa tembok dan jendela. ${ }^{6}$ Dengan demikian diharapkan bisa mengkonstruksi nilai kearifan lingkungan bagi peserta didik. Hal ini juga diterapkan oleh SMP Alam BIS yaitu dimana ruang kelas dibangun tanpa ada skat-skat dinding yang mengelilingi ruang kelas. Pembelajaran di SMP alam yang dilakukan secara out dour berorientasi pada alam sekitar atau lingkungan hidup manusia. Kondisi pembelajaran dengan gaya tersebut menurut Dian Purnama mengajarakan peserta didiknya untuk dapat belajar secara teoritik sekaligus prakteknya dalam kehidupan sehari-hari. ${ }^{7}$ Senada dengan Mulyasa yang megatakan bahwa Interaksi antara siswa dengan lingkungannya disebut sebagai belajar. hingga Terjadi perubahan perilaku yang positif. ${ }^{8}$ Penelitian ini berfokus pada ekologi media pembelajaran PAI dan BP serta intraksi ekologis antara peserta didik dengan media pembelajaran PAI BP

\section{KAJIAN TEORI}

\section{Diskursus Seputar Ekologi Media}

Manusia dan alam semesta tidak bisa Manusia adalah Mikrokosmos, sedangkan kosmos dan lingkungan tempat tinggalnya adalah Makrokosmos. ${ }^{9}$ Dalam hal ini juga pembelajaran juga tidak lepas dari lingkungan. Setidaknya ada tiga asumsi dasar tentang ekologi media yang telah dirumuskan oleh Lynn H.Turner berdasarkan catatannya tentang pengaruh yang ditimbulkan oleh teknologi terhadap masyarakat, gagasan yang membingkai teori tersebut adalah:

1. Every movement and activity in society is influenced by the media.

2. The media organize our experiences and improve our perceptions.

3. Media connects people all over the world. ${ }^{10}$

Berdasarkan asumsi yang pertama dalam tataran pendidikan disekolah menerangkan sebuah gagasan bahwa, peserta didik tidak dapat terhindar dari dampak penggunaan media

\footnotetext{
${ }^{6}$ Ayoe Sutomo. Sekolah Untuk Anakku. (Jakarta: Alex Media Komputido. 2018). 89

${ }^{7}$ Dian Purnama, Cermat Memilih Sekolah Menengah Yang Tepat. (Jakarta: Gagas Media. 2010). 84

${ }^{8}$ E. Mulyasa. Kurikulum Berbasis Kompetensi : Konsep, Karaktristik Dan Implementasinya. (Bandung: Remaja Rosdakarya, 2004). 100

${ }^{9}$ Rusdina, A. (2015). Membumikan etika lingkungan bagi upaya membudayakan pengelolaan lingkungan yang bertanggung jawab. Jurnal Istek, 9(2).224

${ }^{10}$ Richard West \& Lynn H. Turner,. Introducing Communication Theory Analysis And Application. Fourth Edition, (New York: Avenue Of The Americas. 2010), 430
} 
pembelajran. Maka sejauh itu lebih lebar, dalam setiap tindakan yang dilakukan oleh siswa tidak luput dari penggunaan media sebagai sarana maupun fasilitas untuk melakukan sebuah tindakan. Sehingga ada potensi sebuah penjelasan bahwsannya media mampu mempengaruhi atau bahkan mengubah perilaku peserta didik. lebih lanjut McLuhan menerangkan bahwa Whether it's through the games we play, the radios we listen to, or the televisions we watch, these media shape our culture. Simultaneously, media rely on society for "interaction and evolution". ${ }^{11}$

Asumsi yang keuda menerangkan bahwsannya media dapat memperbaiki sebuah pemikiran bahkan hingga tindakan. ${ }^{12}$ Dengan kata lain, menunjukan bahwa peserta didik secara langsung dapat dipengaruhi oleh media. Sebagai contoh, respon perilaku apa yang kemudian memiliki potensi untuk terjadi pada peserta didik, apabila peserta didik menonton sebuah berita tentang krisis moral. Misalnya tentang kekerasan terhadapa anak, penculikan anak, tawuran pelajar, bahkan tentnag penggunaan narkoba dan kehamilan diluar nikah. Potensi diskusi yang terbentuk adalah tentang dekadensi moral dalam masyarakat, namun tanpa disadari mungkin peserta didik justru mengikuti alur cerita dari tragedi tersebut. Sehingga banyak dari kalangan masyarakat yang mengecam tindakan demikian atau bahkan lmendorong pemerintah dalam menegakkan dan membuat peraturan untuk menanggulangi kejadian tersebut.

Asumsi yang ketiga adalah tentang pembentukan jaringan pembelajaran yang seluasluasnya, sehingga akan lebih banyak persepektif pengetahuan maupun budaya yang mampu diakses. Sehingga peserta didik memiliki cukup wawsan global untuk lebih peduli terhadap permasalahan-permasalahan global, agar wawasan tidak terbatas dalam komunitasnya sendiri.

The globe is no more than a village and that we should feel responsible for others. Others are now involved in our lives, as we in theirs. Media Ecology theorists believe that the action of one society will necessarily affect the entire global village. Therefore, floods in Europe, famine in Africa, and war in the Middle East affect the United States, Australia, and China. According to McLuhan, we can no longer live in isolation because of "electronic interdependence. ${ }^{13}$

Teori ekogi media yang dibangun oleh McLuhan memiliki latar belakang yang erat kaitannya dengan aspek historis penggunaan media. Menurutnya penggunaan media sesuai

\footnotetext{
${ }^{11}$ Marshall McLuhan, Lewis H. Lapham, Understanding Media The Extension Of Man, (New York, The MIT Press: 1994), 49

${ }^{12}$ Richard West \& Lynn H. Turner, Introducing . . . ., 431

${ }^{13}$ Marshall McLuhan, Lewis H. Lapham, Understanding . . ., 5
} 
dengan kondisi pada masanya masing-masing. Pada gilirannya McLuhan mengkalisifikasikan media menjadi empat periode.

The essence of a society is defined by the media of the day. They depict four media periods, or epochs, each of which corresponds to the major medium of communication at the time. In each era, media, according to McLuhan, act as extensions of the human senses, and communication (technology) is the major source of social change. ${ }^{14}$

1. The Tribal Era (Face-to-Face Communication and Hearing)

An oral or tribal civilization has stability well beyond what a visual or civilized and fractured world can offer. ${ }^{15}$

2. Literate Era (Seeing/Phonetic Alphabet)

Western man [woman] has done little to research or comprehend the role of the phonetic alphabet in the formation of many of his [her] core cultural patterns.. ${ }^{16}$

3. The Printing Era (Presses/Seeing)

The gift of detachment and noninvolvement-the ability to act without reacting-is perhaps the most significant of typography's gifts to man [woman]. ${ }^{17}$

4. The Information Age (Computer/Seeing, Hearing,)

Because it is an extension of our central nervous system, the computer is by far the most amazing of all technical clothes ever conceived. ${ }^{18}$

\section{Hukum Ekologi Media}

Sebagai bekal untuk menggunaakan teknologi sebagai media dalam kegiatan pembelajaran, setidaknya perlu diketahui ada beberapa hukum media yang menjadi landasan penggunan media menuju kearifan media. Setidaknya ada empat hukum ekologi media menurut McLuhan Yang dikutip oleh Lynn H.Turner yang referensial bagi para guru dalam menggunakan media pembelajaran.

1. Enhacment (peningkatan)

Hukum media yang pertama ini adalah peningkatan, yaitu media yang digunakan sebainya meningkatkan atau memperkuat pengetahuan dan pengalaman peserta didik. ${ }^{19}$

2. Obsolescence (keusangan)

Hukum yang kedua ini menunjukkan sifat regeneratif dari suatu media, sebuah media yang digunakan pada akhirnya akan membuat media yang lainnya usang atau ketinggalan zaman.

3. Retrieval (Pengambilan)

\footnotetext{
${ }^{14}$ Marshall McLuhan, Lewis H. Lapham, Understanding . . ., 7

${ }^{15}$ Marshall Mcluhan, Quentin Fiore, The Medium Is The Massage (Corle Mendera: Gingko Press, 2005). 23

${ }^{16}$ Marshall Mcluhan, Quentin Fiore, The Medium . . ., 82

${ }^{17}$ Marshall McLuhan, Lewis H. Lapham, Understanding . . ., 173

${ }^{18}$ Marshall Mcluhan, Quentin Fiore, The Medium . . .., 3

${ }^{19}$ Richard West \& Lynn H. Turner, Introducing . . . ., 439-440
} 
Hukum ketiga adalah pengambilan, artinya media memulihkan atau mengembalikan sesuatu yang pernah hilang.

4. Reversal (Pembalikan)

Hukum pembalikan adalah media yan memiliki daya dukung sehingga dapat beralih fungsi atau bahkan menghasilkan sesuatu yang lain.

\section{METODE PENELITIAN}

Riset ini dilaksanakan di SMP. Alam Banyuwangi (BIS) Penelitian ini menggunakan teknik penelitian kualitatif berupa studi kasus. Artinya penetian ini mencoba mendeskripsikan subjek penelitian dengan menganalisis fenomena-fenomena yang gerjadi. Pendekatan observasi wawancara dan dokumentasi digunakan untuk memperoleh data. kemudian dikumpulkan guna dianalisis sebagai alat mencari makna yang mendalam tentang sebuah fenomena.

Periset analisis data yang interaktif Menurut Miles, Huberman, dan Saldana, analisis data interaktif harus mencakup proses data sebagai berikut:

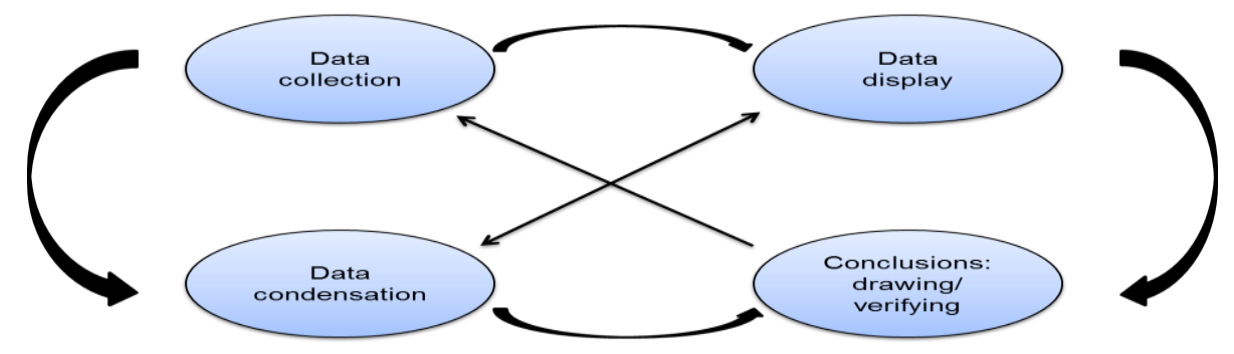

Gambar 3. Komponen-komponen analisis data model interaktif ${ }^{20}$

\section{PEMBAHASAN}

Semua tindakan yang dilakukan oleh penyelenggara pendidikan yang dapat mempengaruhi hasil pendidikan dari segi kondisi lingkungan, seperti keluarga, sekolah, masyarakat, wilayah dan geografi, sejarah masyarakat, politik negara, ilmu pengetahuan dan teknologi di sekitarnya, dan komunitas global. , termasuk dalam praktik pendidikan ekologi. ${ }^{21}$ Contoh metode pengajaran yang menonjolkan tema ekologi manusia dan menggambarkan manusia sebagai bagian dari lingkungan.

Praktik Pendekatan karakter ekologis dapat digunakan dalam pendidikan ekologi. M. Noor Rochman di Holahan menerangkan, yang dimaksudkan dengan karakter ekologis adalah

\footnotetext{
${ }^{20}$ M.B. Miles, A.M. Huberman, dan J. Saldana, Qualitative Data Analysis: A Methods Sourcebook.thired edition. (USA: 2014). Terjemah Tjejep Rohindi Rohdi, UiI-Pers. 14.

${ }^{21}$ Dian Permatasuri. Apa Dan Bagaimana Pendidikan Berwawasan Ekologi? Http://Www.Jugaguru.Com /Article/49/Tahun/2006/Bulan/09/Tanggal/20/Id/146/. Diakses Pada 15 Oktober 2018
} 
tujuan menumbuhkan pola pikir yang sadar lingkungan, mengingat permasalahan ekologi saat ini lebih banyak disebabkan oleh perilaku manusia yang gegabah dalam berinteraksi dengan lingkungannya. ${ }^{22}$ Program Ecological Character Building merupakan salah satu cara untuk mengajak masyarakat berpikir tentang lingkungan. Kurikulum ini mencakup kegiatan yang mengeksplorasi aspek psikologis interaksi manusia dengan alam. Kajian ini mencoba untuk menganalisis lingkungan sebagai media pembelajaran atau pembelajaran yang meangunakan apa yang ada disekitarnya sebagai media pembeajaran

Media yang merupakan alat yang digunakan untuk memberikan informasi atau materi pendidikan kepada siswa dengan konsekuensi mempermudah dalam mencapai tujuaun belajar itu sendiri, dalam praktek penggunaannya tentu melakukan beberpa pertimbanganpertimbangan khusus. Dilain pihak, McLuhan menuturkan bahwasannya The message is the medium, bahwasannya. This is simply to say that each medium, that is, any extension of ourselves, has personal and social ramifications as a result of the new scale that each extension of ourselves, or any new technology, introduces into our activities. ${ }^{23}$

Penggunaan media pembelajaran di SMP Alam Banyuwangi cukup variatif menyesuaikan dengan materi menuntun agar peserta didik mengetahui atau mengenali terlebih dahulu keadaan yang senyatanya. Hal ini menunjukkan kebutuhan media dalam kegaitan belajar, We can't ignore or avoid media, especially if we follow McLuhan's broad definition of what defines media. ${ }^{24}$ Selain itu, Sekolah alam yang mengusung pendekatan terhadap alam dan mendorong peserta didiknya untuk belajar dengan ralitas yang senyatanya. Senada dengan pendapat Nurhadi tentang fungsi Sekolah dengan pembelajaran realistik yaitu Sekolah tidak lagi menjadi beban, melaikan sebuah ralitas hidup yang dijalani oleh pelajar dengan penuh penghayatan. Sekolah menjadi sumber kegembiraan dan bukan sumber stres secara emosioonal yang relative mengurangi gairah belajar peserta didik. Belajar akan lebih meaningfull apabila siswa tahu tidak hanya mengalaminya. ${ }^{25}$ Adapun maksud dari wawasan ekologis disini lebih kepada bagaima kearifan terhadap pemanfaatan lingkungan sebagai media pembelajaran dalam rangka meraih kesalehan ekologis, sebagaimana pendapat Hamzah Tauleka menerangkan

\footnotetext{
${ }^{22}$ M. Noor Rochman Hadjam Dan Wahyu Widhiarso, Budaya . . , 87

${ }^{23}$ Marshall McLuhan, Lewis H. Lapham, Understanding Media The Extension Of Man, (New York, The MIT Press: 1994), 9

${ }^{24}$ Richard West \& Lynn H. Turner, Introducing Communication Theory Analysis And Application. Fourth Edition, (New York, Avenue Of The Americas: 2010), 430

${ }^{25}$ Nurhadi. Pendekatan Kontekstual. (Jakarta: Departemen Pendidikan Nasional, 2002), 1.
} 
bahwa kearifan ekologi merupakan bentuk hubungan dimana manusia belajar melihat alam sebagai kawan kita. ${ }^{26}$

Sebagai sebuah sarana dalam kegiatan belajar, media memiliki peran sentral dalam kegiatan transfer informasi sehinga berdasarkan analisis tertentu kebutuhan terhadap media pembelajaran menjadi sebuah keniscayaan dalam menyampaikan informasi pada peserta didik. People's sentiments, thoughts, and behaviors are shaped by mediated technology, according to the media. ${ }^{27}$ Every move and activity in society is influenced by the media. Our perceptions and experiences are shaped by the media. The media connects the world. ${ }^{28}$

Kendati demikian, pemilihan dan penggunana media pembelajaran hendaklah mempertimbangkan prinsip kesesuaian dan keseimbangan antara materi dan media, kondisi guru dan peserta didik, serta media dengan kondisi lingkungan yang lebih luas sehingga hubungan interaksional antara media dengan masa depan alam berlangsung dengan baik dan mewujudkan kesalehan ekologis. Sehingga peserta didik memiliki cukup wawsan global untuk lebih peduli terhadap permasalahan-permasalahan global, agar wawasan tidak terbatas dalam komunitasnya sendiri.

The globe is no more than a village and that we should feel responsible for others. Others are now involved in our lives, as we in theirs. Media Ecology theorists believe that the action of one society will necessarily affect the entire global village. Therefore, floods in Europe, famine in Africa, and war in the Middle East affect the United States, Australia, and China. According to McLuhan, we can no longer live in isolation because of "electronic interdependence. ${ }^{29}$

Untuk menepis terjadinya krisis ekologis, dalam penggunaan media pembelajaran prinsip keberlanjutan (sustainability) menjadi sebuah keniscayaan agar tidak terjadi pergeseran fungsi ekologis yang melahirkan distabilitas ekosistem, akibat dari terjadinya penurunan jumlah dan kualitas sumber daya alam oleh karena kecerobohan dalam pemilihan dan penggunaan media pembelajaran yang ditandai dengan perilaku eksploitatif dan rendahnya kreatifitas manusia. Menurut Ghazali, jika seseorang memiliki kesalehan ekologis, ia akan mampu memahami, memahami, dan menangkap makna lingkungan, kegunaan dan manfaat, serta sifat keberadaan lingkungan di dunia ini. ${ }^{30}$

\footnotetext{
${ }^{26}$ Hamzah Tauleka, Teologi Lingkungan Hidup Dalam Prespektif Islam, Fakultas Ushuluddin Iain Sunan Ampel. Dalam, Jumarddin La Fua. Aktualisasi Pendidikan Islam Dalam Pengelolaan Lingkungan Hidup Menuju Kesalehan Ekologis, Al-Ta'dib Vol. 7 No. 1 Januari-Juni, 2014, 2.

${ }^{27}$ Richard West \& Lynn H. Turner, Introducing . . , 428

${ }^{28}$ Richard West \& Lynn H. Turner, Introducing . . , 430

${ }^{29}$ Marshall McLuhan, Lewis H. Lapham, Understanding . . , , 5

${ }^{30}$ Bachtiar Ghazali, Lingkungan Hidup Dalam Pemahaman Islam. (Jakarta: Pedomanilmujaya. 1996), 38.
} 


\section{Penggunaan Media Ekologis Pembelajaran Di SMP Alam Banyuwangi}

Berikut uraian beberapa jenis media yang digunakan pada kegiatan pembelajaran dan bagaimana penggunaannya:

\section{Media Grafis}

Media grafis, yang meliputi media visual serta bentuk media lainnya, digunakan untuk menyalurkan komunikasi dari sumber ke penerima yang dituju. Indera penglihatan adalah fokus saluran. Simbol komunikasi visual dituangkan dengan pesan yang ingin disampaikan. dimana indera penglihatan sudah digunakan sebagai penengkap pesan yang ditandai dengan pengenalan huruf atau gambar, sehingga mata memiliki peran yang dominan dalam mengakap sebuah pesan. Kendati demikian, dalam media ini memiliki potensi unutk menciptakan manusia yang bersifat individualistis. Sebab orang akan dengan mudah mendapatkan sebuah informasi tanpa bantuan orang lain, bahkan orang akan bisa berkomunikasi tanpa harus tatap muka. When written communication flourished and the eye became the major sense organ, the literate era began. ${ }^{31}$

Media ini dalam tingkatan modus belajar termasuk dalam media yang memberikan pengalaman pictorial atau gambar (iconic). Azar Arsyad menuturkan bahawannya media yang memeberikan pengalaman pictorial terhdap peserta didik berupa kemampuan untuk memproduksi pengetahuan maupun perilaku melalui lambang-lambang iconic. Sebagai contoh, dengan melihat praktek wudhu melalui gambar bahkan vidio, peserta didik dapat mempelajari dan memahami tatacara berwudhu' meskipun peserta didik belum pernah melakukan kegiatan berwudhu'. ${ }^{32}$

\section{Media Teks}

Media ini membantu peserta didik untuk lebih gampang fokus terhadap materi, sebab dengan cara membaca siswa dapat memperoleh pemahaman terhadap materiIn any literary society, the phonetic alphabet lowers the significance of the other senses of sound, touch, and taste by intensifying and extending the visual function. ${ }^{33}$ Peran mata sebagai media penglihat menjadi titik sentral dalam penggunaan media ini, meskipun dalam hal kebutuhan khusus indera peraba memiliki peran utama dalam menangkap pesan media teks khusus.

Media teks dalam tinjauan historis teori ekologi media yag dijelaskan oleh McLLuhan termasuk dalam literate era, pada era ini masuia sudah bisa membaca dan menulis atau

\footnotetext{
${ }^{31}$ Richard West \& Lynn H. Turner, Introducing . . , 433

${ }^{32}$ Azar Arsyad. Media pembelajaran (Jakarta: rajawali pers, 2010). 8

${ }^{33}$ Marshall Mc Luhan, Lewis H. Lapham, Understanding . . ., 96
} 
melek huruf, sehingga mata memiliki peran yang dominan dalam mengakap sebuah pesan. Pada era ini pula pengetahuan sudah mulai lebih mudah untuk diakses. Kendati demikian, dalam era ini memiliki potensi unutk menciptakan manusia yang bersifat individualistis. Sebab orang akaan dengan mudah mendapatkan sebuah informasi tanpa bantuan orang lain, bahkan orang akan bisa berkomunikasi tanpa harus tatap muka. When written communication flourished and the eye became the major sense organ, the literate era began. ${ }^{34}$

Dengan menggunaka media teks, peserta didik tidak perlu berfokus pada hal-hal lain, peserta didik tidak tertuntut konsentrasinya terhadap banyak hal. Peserta didik cukup dituntut agar senantiasa memperhatikan teks yang dihadapannya

In terms of culture, this clear division and parallelism between the visual and auditory worlds was both crass and cruel. Phonetically transcribed words surrender worlds of meaning and perception that were previously protected by hieroglyphic and Chinese ideogram forms. Men, on the other hand, had no way of transferring from the magically discontinuous and traditional world of the tribal speech to the cool and uniform visual medium through these culturally richer forms of writing. ${ }^{35}$

Media ini juga dipandang efektif dalam membangun motivasi belajar peserta didik. Kendati demikian, media ini dipandang sebagai media yang monoton. Melalui media teks ini pula awalmula signifikansi konstruksi pemikiran dan kebudayan yang bersumber dari kemudahan akses untuk membaca. Only alphabetic civilizations have ever mastered connected lineal sequences as pervasive psychological and social organizational structures. The division of all types of experience into consistent units in order to facilitate speedier action and change of form (applied knowledge).... man and nature alike. ${ }^{36}$

Media ini dalam tingkatan modus belajar termasuk dalam media yang memberikan pengalaman simbolik. Azar Arsyad menuturkan bahawannya media yang memeberikan pengalaman simboloik terhadap peserta didik berupa kemampuan untuk memproduksi pengetahuan maupun perilaku melalui symbol-simbol yang berasal dari membaca atau mendengar. Sebagai contoh, dengan membaca atau mendengar keterangan tentang praktek wudhu melalui teks maupun keterangan guru, peserta didik dapat mempelajari dan memahami tatacara berwudhu' dengan cara mencocokkannya dengan praktek kegiatan

\footnotetext{
${ }^{34}$ Richard West \& Lynn H. Turner, Introducing . . , 433

${ }^{35}$ Marshall Mc Luhan, Lewis H. Lapham, Understanding . . , 95-96

${ }^{36}$ Marshall Mc Luhan, Lewis H. Lapham, Understanding . . , , 98
} 
berwudhu.. ${ }^{37}$ maka dengan kata lain, untuk memeberikan kemampuan yang komprehensif pada peserta didik, media ini membutuhkan kegiatan praktek.

\section{Teknologi}

Teknologi merupakan media pembelajaran dari hasil penemuan-penemuan baru terkait bahan-bahan elektronik yang bisa dimanfaatkan dalam kegiatan belajar. Media jenis ini, dalam persepektif historis ekologi media bisa dikatakan sebagai era eloktronik, yang dicirikhaskan dengan keberadaan TV, telepon, komputer radio, dan internet. Era ini memiliki kemampuan untuk mencover tiga era sebeulumnya, kita dapat menggunakan pesan suara saja melalui lisan, mendokumentai teks dalam komputer, dan lain sebagainya. Kendati demikian, ada beberapa kelemahan pada era ini sebagaimana diungkapkan oleh Lynn H.Turner

Electronic media has dispersed knowledge to the point where individuals are now one of several key sources of information, rather than books being the central repository of information. This epoch has brought us back to a basic reliance on "talking" with one another. The electronic era is an epoch in which electronic media penetrates our senses and allows individuals all over the world to connect. ${ }^{38}$

Pada era ini pula kita perlu untuk memulai tradisi mengevaluasi kembali bagaimana media dapat mempengaruhi penggunannya, sehingga kesimbangan antara indera penangkap pesan perlu sangat dipertimbangkan, penggunaan indera secara bersamaan dalam menyimpulkan sebuah invormasi, sebagi contoh pada saat kita mendengarkan sebuah pesan alangkah baiknya jika kita juga melihat kebenaran pesan tersebut. The expression "ratio of the senses" refers to how humans adjust to their surroundings (through a balance of the senses). ${ }^{39}$

Kecanggihan alat ini bisa menampilkan suara saja, gambar saja maupun suara dengan gambar. Sehingga dalam penerimaan pesannya peserta didik dapat menggunakan indra penglihatan saja atau indra pendengaran saja bahkan gabungan dari indra penglihatan maupun indra pendengaran, dalam mengakses berbagai jenis informasi melalui pesan yang disampaikan oleh media teknologi. Hal ini merupakan diantara bukti pendukung terhadap konsep dual codding hypothesis dari paivio yang dikutip Oleh Azar, Ada dua sistem memori manusia, menurut gagasan itu. Pertama, sistem memori guna megolah symbol verbal. yang

\footnotetext{
${ }^{37}$ Azar Arsyad. Media. . ., 8

${ }^{38}$ Richard West \& Lynn H. Turner, Introducing . . , , 435

${ }^{39}$ Richard West \& Lynn H. Turner, Introducing . . , , 436
} 
selanjutnyadisimpan berbentuk gambaran. Kedua, untuk menafsirkan visual nonverbal yang kemudian disimpan sebagai posisi verbal. ${ }^{40}$ Sehingga peserta didik memiliki cukup wawsan global untuk lebih peduli terhadap permasalahan-permasalahan global, agar wawasan tidak terbatas dalam komunitasnya sendiri.

We should feel accountable for others because the world is nothing more than a village. Others are now as much a part of our life as we are in theirs. Theorists of media ecology think that one society's actions will inevitably effect the entire global village. As a result, floods in Europe, starvation in Africa, and conflict in the Middle East have an impact on the US, Australia, and China. We can no longer exist in solitude, according to McLuhan, because of "electronic interconnectedness". ${ }^{41}$

Teknologi (Media elektronik) dapat memudahkan untuk mengklasifikasikan dan mengenali objek Mampu menunjukkan hubungan spasial suatu objek, dan membantu dalam penerjemahan pengertian abstrak ke dalam istilah konkret. Menurut McLuhan yang dikutip oleh Lynn H.Turner Poetry, fiction, politics, musical theater, and history have all been used to demonstrate how mediated technology influences people's feelings, thoughts, and actions. ${ }^{42}$ Dewasa ini, dengan semakin maraknya penggunaan media berbasis eloktronik, baik berupa perangkat keras maupun jaringan tanpa kabel dalam penggunaannya memerlukan energi listrik, tanpa adanya energi listrik peralatan tersebut tidak bisa dioperasikan. Aspek pertimbangan terhadap penggunaan energi listrik dapat ditunjukkan diantaranya menganai adanya alsan ekonomis dan alasan lingkungan hidup dalam kenyataan ekologis pembangkit listrik. Dalam menanggapi fenomena itu Richard West. Lynn H.Turner mengatakan Technology is frequently referred to as society's most powerful influence. Few can refute this assertion..$^{43}$

\section{Media Lingkungan}

\section{a. Lingkungan Alam}

Segala sesuatu yang alami di alam, seperti keadaan geografis, iklim, suhu udara, musim, curah hujan, flora (tumbuhan), fauna (hewan), dan sumber daya alam, disebut sebagai lingkungan alam (air, hutan, tanah, batu). dan lain-lain). ${ }^{44}$

Dalam beberapa kasus, siswa dapat mempelajari bagian alam ini secara langsung. Siswa akan lebih mudah belajar karena sifat peristiwa alam pada umumnya tidak

\footnotetext{
${ }^{40}$ Azar Arsyad. Media ..., 9

${ }^{41}$ Marshall McLuhan, Lewis H. Lapham, Understanding . . ., 5

${ }^{42}$ Richard West \& Lynn H. Turner, Introducing . . , , 428

${ }^{43}$ Richard West \& Lynn H. Turner, Introducing . . , , 427

${ }^{44}$ Buckley, R. (2000). Neat trends: current issues in nature, eco-and adventure tourism. International
} Journal of Tourism Research, 2(6), 447. 
berubah, tidak seperti di dunia sosial. ${ }^{45}$ Mahasiswa tentu dapat menyaksikan dan mendokumentasikannya, serta perubahan-perubahan yang terjadi, seperti prosedurnya. Kerusakan lingkungan alam, termasuk penyebab masalah seperti erosi, penggundulan hutan, pencemaran air, tanah, dan udara, adalah gejala lain yang dapat diselidiki.

Diharapkan dengan mempelajari lingkungan alam, siswa akan memperoleh pemahaman yang lebih baik tentang materi pelajaran di sekolah dan mengembangkan karakter cinta alam, kesadaran akan perlunya menjaga dan memelihara lingkungan, partisipasi dalam memerangi pencemaran dan lingkungan. kerusakan, dan kemampuan sumber daya alam bagi kehidupan manusia. Menurut Azar, pembelajaran melalui media lingkungan memungkinkan siswa untuk mengungkap keterkaitan yang sangat penting antara ide-ide abstrak dan aplikasi praktis dalam konteks konsep dunia nyata melalui proses penemuan, pemberdayaan, dan hubungan. ${ }^{46}$

\section{b. Lingkungan Sosial}

Lingkungan sosial sebagai media belajar berkenaan dengan interaksi manusia dengan kehidupan bermasyarakat, peserta didik dapat bersinggungan secara langsung dengan kondisi masyarakat, sekaligus mempelajari dan mempraktekkan apa yang ada dalam masyarakat. Lingkungan sosial tepat digunakan untuk mempelajari ilmu-ilmu sosial dan kemanusiaan. Ahmad Rivai menerangkan bahwa, lingkungan sosial memicu interaksi peserta didik dengan kehidupan masyarakat, seperti organisasi sosial, adat dan kebiasaan, mata pencaharian, kebudayaan, kependidikan, kependudukan, struktur pemerintah, agama dan sistem nilai-nilai. Lingkuangan sosial tepat digunakan untuk mempelajari ilmu-ilmu sosial dan kemanusiaan, dalam mengembangakan karakter sosial peserta didik. ${ }^{47}$

Dalam praktek pengajaran penggunaan lingkungan sosial sebagai media dan sumber belajar hendaknya dimulai dari lingkungan yang paling dekat, seperti keluarga, tetangga, rukun tetangga, rukun warga, kampung, desa, kecamatan dan seterusnya. Hal ini disesuaikan dengan kurikulum yang berlaku dan tingkat perkembangan anak didik.

\section{c. Lingkungan Buatan}

Lingkungan yang ketiga adalah lingkungan buatan. Kalau lingkungan alam bersifat alami, sedangkan lingkungan buatan adalah lingkungan yang sengaja diciptakan atau

\footnotetext{
${ }^{45}$ S. Nasution, Didaktik . . , 137

${ }^{46}$ Azar Arsyad. Media. . . , 145

${ }^{47}$ Ahmad Rivai, Media Pengajaran, (Bandung: Sinar Baru, 1997).
} 
dibangun manusia untuk tujuan-tujuan tertentu yang bermanfaat bagi kehidupan manusia. Lingkungan buatan antara lain adalah irigasi atau pengairan, bendungan, pertamanan, kebun binatang, perkebunan, penghijauan, dan pembangkit tenaga listrik. Siswa dapat mempelajari lingkungan buatan dari berbagai aspek seperti prosesnya, pemanfaatannya, fungsinya, pemeliharaannya, daya dukungnya, serta aspek lain yang berkenaan dengan pembangunan dan kepentingan manusia dan masyarakat pada umumnya. ${ }^{48}$ Lingkungan buatan dapat dikaitkan dengan kepentingan berbagai bidang studi yang diberikan di sekolah. Menurut Azar, belajar dengan menggunakan media lingkungan memungkinkan peserta didik menemukna hubungan yang sangat bermakna antara ide-ide abstrak dan penerapan praktis didalam konteks dunia nyata konsep dipahami melalui proses penemuan, pemberdayaan dan hubungan. ${ }^{49}$

\section{d. Lingkungan keluarga}

Pada taraf anak yang sudah mulai dewasa (bukan balita) peran keluarga dalam memberikan pendidikan baik sebagai sumber belajar maupun sebagai media pembelajaran bagi anak perannya mulai mengalami pergeseran dengan adanya pendidikan-pendidikan lain diluar dari keluarga. Kendati demikian, keluarga tetaplah menjadi sarana pendidikan yang memiliki pengaruh signifikan dalam memberikan pengalaman belajar bagi anak. Zakiah Daradjat mengatakan bahwa orang tua merupakan pendidik utama dan pertama bagi anak-anak mereka, karena dari merekalah anak mula-mula menerima pendidikan. Dengan demikian bentuk pertama dari pendidikan terdapat dalam kehidupan keluarga. ${ }^{50}$

Pergeseran peran keluarga dalam memberikan pendidikan oleh lembaga-lembaga pendidikan, sebaiknya tidak menjadikan lembaga pendidikan (diluar keluarga) menceraikan hubungan pendidikan anak dengan keluarga. Keluarga sebagai mikrosistem pendidikan anak tetap perlu dilibatkan dalam kegiatan belajar anak meskipun tampat tinggal anak sudah tidak lagi bersama dengan orang tua.

Menurut Fuad Ihsan, tanggung jawab pendidikan oleh kedua orang tua meliputi:

1) Memelihara dan membesarkannya. Tanggung jawab ini merupakan dorongan alami untuk dilaksanakan, karena anak memerlukan makan, minum dan perawatan, agar ia dapat hidup secara berkelanjutan.

\footnotetext{
${ }^{48}$ Mohamad Maulidin Alif Utama, A. Ekologi Media Pembelajaran Pendidikan Agama Islam dan Budi Pekerti di SMP Alam Banyuwangi Islamic School. Jurnal Sajie. h. 234

${ }^{49}$ Azar Arsyad. Media. . . , 145

${ }^{50}$ Zakiah Daradjat, Peranan Agama dalam Kesehatan Mental, (Jakarta: Gunung Agung, 1973). 35.
} 
2) Melindungi dan menjamin kesehatannya, baik secara jasmani maupun rohani dari berbagai gangguan penyakit atau bahaya lingkungan yang dapat membahayakan dirinya.

3) Mendidiknya dengan berbagai ilmu pengetahuan dan keterampilan yang berguna bagi hidupnya, sehingga apabila ia dewasa ia mampu berdiri sendiri dan membantu orang lain serta melaksanakan fungsi kekhalifahannya.

4) Membahagiakan anak untuk dunia dan akhirat dengan memberinya pendidikan agama sesuai dengan tuntunan Allah sebagai tujuan akhir hidup muslim.

\section{Manusia} Tanggung jawab ini dikategorikan juga sebagai tanggung jawab kepada Allah. ${ }^{51}$

Media berbasis manusia yang merupakan media tertua yang digunakan dalam menyampaikan sebuah pesan atau informasi. Dimana tatap muka dan kontak pendengaran menjadi kunci dari media ini. Dalam persepektif historis teori ekologi media penggunaan media jenis ini digambarkan dengan istilah tribal era yaitu An oral or tribal society has the means of stability far beyond anything possible to a visual or civilized and fragmented world. ${ }^{52}$

Pada era ini pendengaran memiliki peran yang paling dominan dalam menangkap pesan yang disampaikan oleh media, atau bahkan pendengaran merupakan perangkat satusatunya dalam menangkap pesan, yang ditandai dengan kemampuan manusia untuk mendengarkan tanpa adanya kemampuan untuk menyensor atau menganalisis pesan dari media. Era ini dicirikan dengan tradisi lisan untuk bercerita, dimana orang akan berbicara tentang tradisi, ritual, maupun nilai-nilai dalam sebuah masyarakat. Sehingga indra pendengaran berupa telinga memiliki peran inti dalam era ini, dan pendengaran merupakan hal yang paing dipercaya. Tribal era age when oral tradition was embraced and hearing was the paramount sense. ${ }^{53}$

Media manusia seperti misalnya guru, memiliki potensi penambahan atau bahkan pengurangan terhadap informasi dari pesan yang hendak disampaikan. Hal ini mungkin merupakan pengaruh yang timbul dari media (manusia) itu sendiri. Diantara peristilahan media manusia secara teoritis dijelaskan oleh Socrates yang pada gilirannya dalam dunia pembelajaran akrab diistilahkan dengan metode Socrates. Secara teoritis, metode Socrates dimplementasikan dengan praktik kegiatan pembelajaran yang dilakukan dengan percakapan atau perdebatan yang dilakukan oleh dua orang atau lebih yang saling berdiskusi dan disajikan dengan deretan pertanyaan maupun permasalahan untuk kemudian dibahas

\footnotetext{
${ }^{51}$ Fuad Ihsan, Dasar-dasar Kependidikan, (Jakarta: Rineke Cipta, 1997), 94

${ }^{52}$ Marshall Mcluhan, Quentin Fiore, The Medium . . ., 23

${ }^{53}$ Richard West \& Lynn H. Turner, Introducing . . . , 433
} 
bersama untuk menemukan jawabannya ${ }^{54}$ Metode ini bercirikhaskan dialektik, konversasi, tentatif, empiris, induktif dan konseptual. Metode tersebut dapat diimplementasikan dalam kegiatan belajar mengajar dengan beberapa langkah berupa menyiapkan deretan pertanyaan, kemudian guru menanyakannya pada peserta didik, motivasi urgensi jawaban dari pertanyaan tersebut dan tutun peserta didik untuk mengeksplorasi pengetahuan. In speech we tend to react to each situation that occurs, reacting in tone and gesture even to our own act of speaking. ${ }^{55}$

\section{Interaksi Ekologis Peserta Didik Dengan Media Pembelajaran Di SMP Alam Banyuwangi}

Interaksi antara media dengan peserta didik merupakan suatu uraian tentang pengaruh apa yang ditimbulkan oleh media terhadap peserta didik dan sebaliknya. Berdasarkan hasil penggalian informasi yang dilakukan di SMP Alam Banyuwangi, melalui interaksi yang terjadi antara media dengan peserta didik dapat diklasifikasikan dengan fungsi sebagai berikut:

\section{Interaksi Yang Berfungsi Untuk Menarik Perhatian (Atensi)}

Fungsi atensi atau perhatian, merupakan interaksi awal yang terjadi antara peserta didik dengan media pembelajaran, dengan menggunakan suatu media yang bersifat unik atau menarik, dapat menimbulkan respon dari peserta didik berupa pemusatan perhatian peserta didik terhadap media yang sedang digunakan.

Interaksi ini timbul dari kemampuan media dalam menghipnotis peserta didik, sehingga terdorong perhatiannya untuk terkonsentrasikan pada media. Yang pada gilirannya menjadi konsentrasi peserta didik tertuju pada pesan yang hendak disampaika oleh media tersebut.

Melaluai interaksi yang terjadi siswa dapat tertarik dan terarahkan perhatiannya untuk berkonsentrasi kepada pesan atau isi pelajaran yang ditampilkan atau menyertai pesan yang disampaikan oleh media tersebut. Seringkali pada awal pelajaran siswa tidak tertarik dengan materi pelajaran atau mata pelajaran itu merupakan salah satu pelajaran yang

\section{Interaksi Yang Berfungsi Untuk Merubah Sikap (Afektif)}

Afektif yang jika ditranseliterasikan kedalam bahasa Indonesia memiliki arti sebagai sikap, dalam hal ini pengaruh yang terjadi antara media dengan peserta didik adalah yang berkaitan dengan sikap yang lahir melalui respon peserta didik terhadap

\footnotetext{
${ }^{54}$ Azar Arsyad. Media Pembelajaran. (Jakarta: rajawali press. 2010). 82

${ }^{55}$ Marshall Mc Luhan, Lewis H. Lapham, Understanding . . , 90
} 
media. Sikap tersebut bisa berupa emosi peserta didik saat dan setelah melihat media, dimana emosi tersebut dapat diketahui dengan gejala-gejala yang timbul dari peserta didik, seperti misalnya rasa senang terhadap media, rasa bosan terhadap media, perubahan sikap/perilaku dan lain sebgainya. Pada saat melihat sebuah gambar yang dilekatkan pada papan tulis, memiliki kemampuan merubah sikap peserta didik dari awalnya yang biasa saja ketika melihat papan tulis, namun setelah dilekatkan sebuah gambar terjadi sebuah respon berupa seuara gemuruh yang menandakan ketertarikan dan rasa senag peserta didik terhadap media.

Pengaruh yang timbul dalam ranah afeksi ini cukup signifikan dalam penangkapan pesan yang disampaikan media. Misalnya ketika seorang peserta didik membuka sebuah channel youtube, dia akan mellihat sebuah vidio ceramah salah seorang ustadz, kemudian yang potensi yang terjadi diantara perubahan sikapnya si peserta didik yang menonton tersebut akan menirukan gaya penceramah tersebut baik sikap maupun pemahamannya.

\section{Interaksi Yang Berfungsi Untuk Merubah Pengetahuan (Kognitif)}

Dalam interaksi antara media dan peserta didik diantaranya ada pengaruh yang berupa sisitem kognitif peserta didik. Sistem kognitif yang dimaksudkan disini misalnya seperti timbulnya pemikiran kritis dan analitis peserta didik terhadap materi yang terstimulasikan melalui media pembelajaran. Inteaksi yang terjadi antara media (pesan) dengan peserta didik mampu merubah pola pikir dan mensistemasikan pemikiran peserta didik itu sendiri. Media to suggest that mediated technology shapes people's feelings, thoughts, and actions. ${ }^{56}$

\section{Interaksi Yang Berfungsi Untuk Kompensatoris}

Adalah pengganti peran suatu media dengan media yang lainnya, ataupun pertukaran antara media dengan pesan yang berfungsi untuk menyampaikan pesan pada peserta didik. Ini menunjukkan sifat regeneratif dari suatu media, sebuah media yang digunakan pada akhirnya akan membuat media yang lainnya usang atau ketinggalan zaman. Misalnya saat sebuah media mengalami keusangan, maka dibutuhkan peran pengganti media sebagai pembaharu media pembelajaran. Sebagai contoh, televisi sebagai media pembelajaran akan menggantikan peran radio sebagai media, maka tidak jarang dalam ranga mendapatkan sebuah informasi justru memilih beralih dari radio ke

\footnotetext{
${ }^{56}$ Richard West \& Lynn H. Turner, Introducing Communication Theory Analysis And Application. Fourth Edition, (New York, Avenue Of The Americas: 2010), 428
} 
televisi. Internet juga membuat keusangan misalnya untuk mengetahui suatu tempat tertentu kita tidak perlu menggunakan peta dan datan ke wilayah tersebut. Obsolescence law that states media eventually render something out of date. ${ }^{57}$ Pada posisi kompensatoris, media pembelajaran dapat memenuhi tiga fungsi utama apabila media itu digunakan untuk perorangan, kelompok, atau kelompok pendengar yang besar jumlahnya, yaitu: Memotivasi minat atau tindakan, menyajikan informasi, memberi instruksi.

\section{Interaksi Yang Berfungsi Untuk Sustainebility}

Merupakan interaksi yang berfungsi dalam pendayaguanaan media pembelajaran yang memiliki nilai-nilai pemeliharaan dan pelestarian demi kelangsungan alam dimasa-masa mendatang. Dengan kata lain, sustanbelity media merupakan proses perubahan dimana eksploitasi sumberdaya, arah investasi, orientasi pengemabangan teknologi dan sistem kelembagaan, seluruhnya memiliki kesesuaian dan keselarasan dalam mengembangkan potensi dan meningkatkan komeptensi peserta didik (manusia pada umumnya) pada saat ini dan dimasa yang akan datang. Sebagaimana diterangkan oleh berbagai sumber bahwasannya sekolah alam yang mengusung pendekatan kealaman maka etika terhadap alam pun menjadi kebutuhan pokok dalam kegiatan belajar.

Kontribusi pemahaman mendasar terkait sustainbility media sebagaimana diuraikan diatas, berguna untuk membuka ruang diskusi yang baru, yang pada awalnya diskusi istilah penggunaan media secara eksklusif dikaitkan dengan nilai-nilai efektifitas dan efisiensi saja. Pada tataran ini pertimbangan baru akan dilahirkan untuk mencapai kelangsungan dan keberlanjutan alam.

Sustainbility media berimplikasi logis terhadap penguatan dan pengembangan kompetensi peserta didik, mendorong peserta didik untuk berkontribusi dan berpartisipasi aktif dalam kegiatan pembelajaran yang berkelanjutan. Melalui penjelasan ini dapat dipahami bahwa kompetensi dasar dan ketrampilan peserta didik seperti membaca, menulis, maupun berhitung. Yang pada gilirannya (kelanjutannya) ditingkatkan pada kompetensi yang lebih tinggi seperti kreativitas, pemikiran yang berorientasi pada pemecahan masalah, dan kemampuan untuk melakukan tindakan yang terampil.

\footnotetext{
${ }^{57}$ Richard West \& Lynn H. Turner, Introducing Communication Theory Analysis And Application. Fourth Edition, (New York, Avenue Of The Americas: 2010), 440
} 


\section{KESIMPULAN}

Penggunaan media pembelajaran yang berorientasi pada ketercapaian tujuan pembelajaran dan pemilihan media yang menghindari perilaku ekploitatif meskipun dengan alasan efektifitas dan efisiensi. Dan interaksi antara peserta didik dengan media pembelajaran yang mengedepankan etika pelestarian alam menggeser paradigma antroposentris dalam memanfaatkan lingkungan pada paradigma biosentris yang mengusung nilai-nilai menghargai dan menghormati lingkugan dalam rangka pelstarian lingkungan yang kemudian berakhir pada taraf nilai kearifan ekologis.

a. Penggunaan media ekologis pembelajaran Di SMP Alam Banyuwangi yaitu: Media grafis, Media Teks, Media, Media lingkungan,dan Media manusia.

b. Interaksi Ekologis Peserta Didik Dengan Media Pembelajaran Di SMP Alam Banyuwangi yaitu: Interaksi yang berfungsi untuk menarik perhatian (atensi), interaksi yang berfungsi untuk merubah sikap (afektif), interaksi yang berfungsi untuk merubah pengetahuan (kognitif), interaksi yang berfungsi untuk kompensatoris, dan interaksi yang berfungsi untuk sustainebility.

\section{DAFTAR PUSTAKA}

Arsyad, Azar, 2010. Media pembelajaran (Jakarta: rajawali pers).

Buckley, R. (2000). Neat trends: current issues in nature, eco-and adventure tourism. International Journal of Tourism Research, 2(6)

Daradjat, Zakiah, 1973. Peranan Agama dalam Kesehatan Mental, (Jakarta: Gunung Agung).

Ghazali, Bachtiar. 1996. Lingkungan Hidup Dalam Pemahaman Islam. (Jakarta: Pedoman ilmu jaya).

Hadjam, M. Noor Rochman Dan Wahyu Widhiarso. 2003. Budaya Damai Anti Kekerasan (Peace And Anti Violence), (Jakarta: Ditjen Dikmenum).

Huberman, M.B. Miles, A.M. dan J. Saldana, 2014. Qualitative Data Analysis: A Methods Sourcebook.thired edition. (USA). Terjemah Tjejep Rohindi Rohdi, UiI-Pers.

Ihsan, Fuad. 1997, Dasar-dasar Kependidikan, (Jakarta: Rineke Cipta).

McLuhan, Marshall, Lewis H. Lapham, 1994. Understanding Media The Extension Of Man, (New York: The MIT Press).

Mcluhan, Marshall, Quentin Fiore, 2005, The Medium Is The Massage (Corle Mendera: Gingko Press). 
Mulyasa, E. 2004. Kurikulum Berbasis Kompetensi : Konsep, Karaktristik Dan Implementasinya. (Bandung: Remaja Rosdakarya).

Nurhadi, 2002. Pendekatan Kontekstual. (Jakarta: Departemen Pendidikan Nasional).

Permatasuri, Dian. Apa Dan Bagaimana Pendidikan Berwawasan Ekologi? Http://Www.Jugaguru.Com/Article/49/Tahun/2006/Bulan/09/Tanggal/20/Id/146/.

Diakses Pada 15 Oktober 2018

Purnama, Dian. 2010, Cermat Memilih Sekolah Menengah Yang Tepat. (Jakarta: Gagas Media). Rivai, Ahmad, 1997. Media Pengajaran, (Bandung: Sinar Baru).

Rusdina, A. (2015). Membumikan etika lingkungan bagi upaya membudayakan pengelolaan lingkungan yang bertanggung jawab. Jurnal Istek, 9(2).

S. Nasution, 1995, Didaktik Asas-Asas Mengajar, (Jakarta: Bumu Aksara).

Suryadi, Rudi Ahmad, 2015. Kenali Dirimu: Upaya Memahami Manusia Dalam Al-Qur'an. (Yogyakarta: Depublish).

Sutomo, Ayoe. 2018. Sekolah Untuk Anakku. (Jakarta: Alex Media Komputido).

Tauleka, Hamzah Teologi Lingkungan Hidup Dalam Prespektif Islam, Fakultas Ushuluddin Iain Sunan Ampel. Dalam, Jumarddin La Fua. Aktualisasi Pendidikan Islam Dalam Pengelolaan Lingkungan Hidup Menuju Kesalehan

UU. Sisdiknas. Bab III Pasal 4 Ayat 6

West, Richard \& Lynn H. Turner, 2010. Introducing Communication Theory Analysis And Application. Fourth Edition, (New York: Avenue Of The Americas).

Wmk, Anwari.2010. Pendidikan Tentang Ekologi. Dalam, Setya Raharja, Jurnal Pendidikan Ekologi: Pemberdayaan Lingkungan Sekitar Untuk Pembelajaran. Uny.

Yayasan Penyelenggara Penerjehal Al-Qur'an. 2009. Al-Qur'an Terjemah Tiga Bahasa. (Depok: Al-Huda Kelompok Gema Insani). 